\title{
Energy Consumption Pattern in Rolling Mill Company, Kano Northwest Nigeria
}

\author{
Abdullahi Ahmed ${ }^{1}$, Bashir Isyaku Kunya ${ }^{1}$, Salihu Omonowo Siyaka ${ }^{2}$ \\ ${ }^{1}$ Department of Mechanical Engineering, Kano University of Science and Technology, Wudil Kano, Nigeria \\ ${ }^{2}$ Department of Mechanical Engineering Technology, Federal Polytechnic, Nasarawa, Nigeria \\ Email address: \\ abdula2k2@yahoo.com (A. Ahmed)
}

To cite this article:

Abdullahi Ahmed, Bashir Isyaku Kunya, Salihu Omonowo Siyaka. Energy Consumption Pattern in Rolling Mill Company, Kano Northwest Nigeria. American Journal of Modern Energy. Vol. 3, No. 5, 2017, pp. 90-94. doi: 10.11648/j.ajme.20170305.11

Received: May 14, 2017; Accepted: July 4, 2017; Published: September 6, 2017

\begin{abstract}
The electrical and fuel energy consumption for seven years period was collected for rolling mill company, Kano northwest Nigeria. Monthly energy consumption data were gathered and analyzed. The average electrical energy and thermal energy consumption per tonne of product for the period considered are 34.04GJ/Tonne and 99.74GJ/Tonne respectively. The energy end users were identified as electric furnace, DC main motor, Compressor machine, Air-conditioning, Lightning and Electrical equipment. Regression techniques were used to correlate the monthly energy consumption with product weights in Tons. The Coefficient of determinant (R2) for electrical energy consumption was 0.8458 while R2 for fuel oil energy consumption was 0.7773 indicating strong correlation for electrical and fuel oil energy consumption.
\end{abstract}

Keywords: Electrical Energy, Fuel Energy, Regression, Correlation, Equipment

\section{Introduction}

Energy is a primary input for almost all economic activities and is, therefore vital for the improvement in quality of life. The International Energy Agency (IEA) has gathered data from various sectors on energy consumption trends. During the last two decades $(1984-2004)$ primary energy has grown by $49 \%$ with an average annual increase of $2 \%[4]$.

The industrial sector consumes over one third of any nations primary energy but government and private enterprises have kept watchful eyes in their use of energy by ensuring efficient utilization of their energy resources [5], but traditionally energy conservation and energy efficiency has not been given high priority for many industries and private sectors in Nigeria, this was because of low energy price which was sustained by government subsidy on various forms of energy especially fossil fuel and electricity.

The concentration of greenhouse gases (GHG) resulting from anthropogenic action such as emission from factories and mobile motors has increased markedly since the industrial revolution. To minimize the environmental impact of GHG (such as global climate change and global warming), the United Nations Framework Convention on Climate
Change (UNFCCC) initiated efforts in Rio de Janeiro in 1992 to consider strategies for reducing GHG emissions. In December 1997, the third conference of parties (COP-3) of the UNFCCC was held in Kyoto in Japan and resulted in the so- called Kyoto Protocol. In Kyoto, the developed countries committed themselves to reducing emissions of carbon dioxide $\left(\mathrm{CO}_{2}\right)$, methane $\left(\mathrm{CH}_{4}\right)$ and nitrous oxide $\left(\mathrm{N}_{2} \mathrm{O}\right)$ by 6$8 \%$ compared, with 1990 emission levels in the period 2008 2012 [7]. Since GHG emission are recognized to come primarily from energy consumption, climate change is a growing global concern. The environmental externalities associated with energy consumption have become a new focus of international concern. Improving energy efficiency is the key to reducing GHG emissions. Therefore, energy research organizations and governments are actively engaged in developing methods in assessing energy efficiency. This assessment can be provide a reference for establishing energy policy and can simultaneously reduce GHG emissions. Among the various sectors contributing to GHG emissions, the contribution of the industrial sector was significant. Thus, mitigating GHG emission from the industrial sector offers the best means of reducing overall GHG emission [2].

The scarcity and undesirable side effects of careless utilization of energy resources on economics and ecology require careful analysis and planning for proper energy 
consumption. In this regard, exergy analysis appears to be a significant tool in [8].

a addressing the impact of energy- resource utilization on the environment,

b furthering the goal of more efficient energy- resource utilization,

c enabling locations, types and true magnitudes of wastes and losses to be determined,

$\mathrm{d}$ revealing whether or not and how it is possible to design more efficient energy systems by reducing the efficiencies in

e in the existing systems,

f providing a sustainable development as a result of sustainable supply of energy resources, and

$\mathrm{g}$ distinguishing the high quality and low quality energy resources.

Presently, energy supply in Nigeria is a major problem for both large and small scale purposes. Highly centralized production and distribution units have not been equally distributed thus becomes inadequate in meeting the economic needs of both urban and rural populace in Nigeria. With respect to this problem, this calls for efficient energy conservation measure in which energy audit is a key method.

During the past two decades, the concept of exergy has received great attention from scientist, researchers and engineers and been applied to various industrial sectors and thermal processes. Recently, much attention has been paid to the energy -utilization assessments in -order to attain energy savings, and hence financial savings. The energy utilization of a country can be assessed using exergy analysis to gain insights into its efficiency. In this context, researchers have carried out number of studies in order to evaluate how much energy could be saved without affecting productivity.

Energy and exergy utilization in the public and private sector of Saudi Arabia by considering the energy and exergy flows for the years between 1990-2001. Energy and exergy analyses for the public and private sector are undertaken to study the energy and exergy efficiencies [1]. These sectoral efficiencies are then compared, and energy and exergy flow diagrams for the public sector over the years are presented, respectively. Energy and exergy efficiencies of the public and private sector are compared for its six sub sectors, namely commercial, government streets. Mosques, hospitals and charity association, particularly illustrated for the year 2000 . Hospital sub-sector appears to be the most energy efficient sector and may assist energy policy makers of the country.

Electricity use characteristics of purpose-built office buildings in subtropical climates were studied by [6] in the study twenty (20) air conditioned office buildings in the public sectors inn subtropical Hong Kong were investigated. Monthly electricity consumption data were gathered and analysed. The annual electricity per unit gross floor area ranged from 163 to $389 \mathrm{~kW} / \mathrm{m}^{2}$, with a mean of $270 \mathrm{kWh} / \mathrm{m}^{2}$. Detailed energy audits and site surveys were conducted to obtain a breakdown of the energy use. The percentage consumption for the four major electricity users, namely heating, ventilation and air condition, lightning, electrical equipment and lifts and escalators were $47.5 \%$. 27.4\%, $21.8 \%$ and $3.3 \%$ respectively. Regression technique was used to correlate the monthly electricity use with the design and climatic variables $[2,3]$.

Electrical energy consumption in cement company, Ewekoro, Nigeria [8] and 5 years (1997- 2001) was considered in their study. In the study, it was found that the energy intensity was found to be between 120 $349 \mathrm{kWh} /$ Tonne of cement, also an increase of $82 \%$ was recorded in 1998 in a bag of cement when compared with the previous records. Electrical energy consumption at the raw mill sector machinery was $41 \%$ while the dispatch sector was $10 \%$ in electrical energy consumption.

In this presentation, seven years $(2000$ - 2006) data for product weight, electrical and fuel oil energy consumption were obtained from the steel rolling mill company and Power Holding Company Nigeria (PHCN), regression techniques was used in the analysis.

The aim of this present work, is to study how energy is been used, data acquisition and formulating energy equations using linear regression for effective growth of the Company.

\section{Data Collection and Analysis}

In this study, data for product weight (iron rods), electrical and fuel energy consumption in a rolling mill company, Kano, Nigeria are investigated. Seven years monthly and yearly data $(2000-2006)$ from the rolling mill Company, Kano and PHCN were used. In collecting data for energy consumption and identification of energy carriers and consumers, one can construct various types of energy use profiles, comparison tables and corresponding correlation plots. In examining further the measured energy consumption data for the company, different energy characteristics and patterns can be established. In investigating and evaluating the company energy use, different category of loads was considered. The first categories are equipment used in the company; examples are electric arc furnace, electric motor, compressor machine, air conditioning plants and systems, office equipment and other electrical appliances. The second category is the product energy consumption, which is defined as the quantity of energy used by each equipment within a stipulated production time.

\subsection{Regression Analysis}

The electrical power and fuel oil consumption can be obtained from the equation (1) and (2) below [7, 13];

$$
\begin{aligned}
& y_{1}=a+b_{1} x_{1}+b_{2} x_{2} \\
& y_{2}=a+b_{1} x_{1}+b_{2} x_{2}
\end{aligned}
$$

$y_{1} \& y_{2}=$ dependent variables

$\mathrm{a}=$ constant

$b_{1} \& b_{2}=$ independent variable coefficient

$x_{1} \& x_{2}=$ independent variables 
Alternatively, the t-statistics for variables coefficient $x_{1}$ and $x_{2}$ are computed using equation (3) below [4];

$$
t-\text { statistics }=\frac{\text { var iable }- \text { coefficien } t}{\text { var iable }-s \tan \text { dard }- \text { error }}
$$

The Mean Bias Error provides information on the long term performance of the regression equation model. Below shows relation for Mean Bias Error (MBE) [3].

$$
\text { Mean Bias Error }(M B E)=\sum_{i}^{12} \frac{\left(x_{i}-y_{i}\right)}{12}
$$

\subsection{Energy Use Index}

The amount of energy used per tonne of product is computed using the relation below [1];

$$
E U I=\frac{\text { Annual Energy Consumption }}{\text { Annual Product Weight }}
$$

\subsection{Power Factor Analysis}

Irrespective of the nature of voltage and current, the power factor may be define as the ratio of true power consumed $(\mathrm{kW})$ to apparent power $(\mathrm{kVA})$ which is the product of voltage and current $[6,12]$.

$$
\text { Power factor }=\frac{\text { True Power }(\mathrm{kW})}{\text { Apparent Power }}
$$

To obtain an accurate assessment of the power factors of the equipment, kilowatt hour $(\mathrm{kWh})$ reading of the equipment were taken within a specified production time.

\subsection{Energy Usage \& Cost Analysis}

The cost of energy consumed were computed, also cost analysis was made in using energy efficient motors instead of the standard motor used by the company, the amount of $\mathrm{kW}$ saved is stated in the conclusion $[9,11]$.

$$
\begin{gathered}
\text { Cost of power consumed in } k W h=\frac{\operatorname{Power}(W) * t * \operatorname{Cost} / \mathrm{kWh}}{1000} \\
k W_{\text {saved }}=h . p * 0.746 *\left[\frac{100}{E_{\text {STD }}}-\frac{100}{E_{E E}}\right]
\end{gathered}
$$

ESTD $=$ Efficiency of standard motor

$\mathrm{EEE}=$ Efficiency of energy efficient motor

Annual savings in Naira due to differnce in efficiency [10,14];

$$
h . p * 0.746^{*} L^{*} C^{*} N *\left[\frac{100}{E_{S T D}}-\frac{100}{E_{E E}}\right]
$$

$\mathrm{L}=\mathrm{Load}$

$\mathrm{C}=$ Cost of energy per $\mathrm{kWh}$

$\mathrm{N}=$ Number of poles

$$
\text { h. } \mathrm{p}=\text { Horse power }
$$

\section{Results and Discussion}

Data for energy consumption and product weights for the period considered were gathered and analyzed. Table 1 shows the annual product weight in tonnes, electrical energy $(\mathrm{kWh})$ and fuel oil consumption in (litres) for the period $(2000-2006)$. Table 2 presents the results of regression analysis of the electrical energy and fuel oil energy. From the table it can be seen that $\mathrm{R} 2$ values are high and ranges from 0.703487 to 0.886193 indicating strong correlation for electrical and fuel energy consumption.

The equation $y_{2}=17161.96-134.87 x_{1}+606.80 x_{2}$ and $y_{1}=-245801.75-686.31 x_{1}+4517.69 x_{2}$ are used in computing the predicted electrical and fuel energy consumption for year 2000 respectively, equations for the remaining years are also generated from the regression results as presented in table 2 .

Table 1. Annual electricity consumption, fuel oil consumption and product weight.

\begin{tabular}{llll}
\hline Year & $\begin{array}{l}\text { Product } \\
\text { Weight (Ton) }\end{array}$ & $\begin{array}{l}\text { Electrical Power } \\
\text { Consumption (kWh) }\end{array}$ & $\begin{array}{l}\text { Fuel Oil Consumption } \\
\text { (Litres) }\end{array}$ \\
\hline 2000 & 2330 & 3292721 & 1005554 \\
2001 & 2320 & 3575729 & 1028841 \\
2002 & 2515 & 3404432 & 985524 \\
2003 & 2675 & 3861645 & 1026671 \\
2004 & 2595 & 3788078 & 988978 \\
2005 & 2530 & 3794938 & 1036112 \\
2006 & 2130 & 3449738 & 1016490 \\
\hline
\end{tabular}

Table 2. Coefficient of determinant (R2), intercept(a), 1st and 2nd independent variable coefficient ( $b 1 \& b 2)$.

\begin{tabular}{lllll}
\hline Year (Elect.) & a & b1 & b2 & R2 \\
\hline 2000 & -245801.75 & -686.31 & 4517.69 & 0.886193 \\
2001 & -262523.86 & -962.56 & 4855.07 & 0.843666 \\
2002 & -361125.77 & 818.94 & 4435.70 & $0-844015$ \\
2003 & -328720.50 & 1481.64 & 4009.87 & 0.870102 \\
2004 & -337452.10 & 924.56 & 4586.70 & 0.822295 \\
2005 & -283264.63 & 53.84 & 4666.85 & 0.885091 \\
2006 & -151373.79 & -748.12 & 3840.32 & 0.769356 \\
Year (Fuel) & $\mathbf{a}$ & $\mathbf{b 1}$ & $\mathbf{b 2}$ & $\mathbf{R 2}$ \\
2000 & 17161.96 & -134.87 & 606.80 & 0.832420 \\
2001 & 10835.35 & -143.98 & 656.57 & 0.872699 \\
2002 & -14740.51 & 63.43 & 702.21 & $0-794225$ \\
2003 & -25000.15 & 272.77 & 665.54 & 0.758983 \\
2004 & -43761.07 & 112.26 & 935.70 & 0.753590 \\
2005 & -22777.39 & 260.72 & 737.73 & 0.703487 \\
2006 & 1062.46 & -625.78 & 954.59 & 0.725632 \\
\hline
\end{tabular}

Figure 1 shows the amount of energy consumed per tonne of product which is expressed in GJ. It can be seen from the figure that electrical energy is more consumed than the thermal energy in producing the products throughout the seven years considered in the research work. Figure 2 shows bar chart for actual and predicted fuel energy consumption and figure 3 shows the actual and predicted electrical energy consumption, the predicted fuel energy consumption is obtained from the regression equation. It can be seen from both charts that the differences in energy consumption for 
both actual and predicted consumption is quite minimal. While figure 4 shows residuals for both electrical and fuel energy consumption. A positive residual indicates that the actual consumption is greater than the predicted consumption and a negative residual indicates that the predicted consumption is greater than the actual consumption.

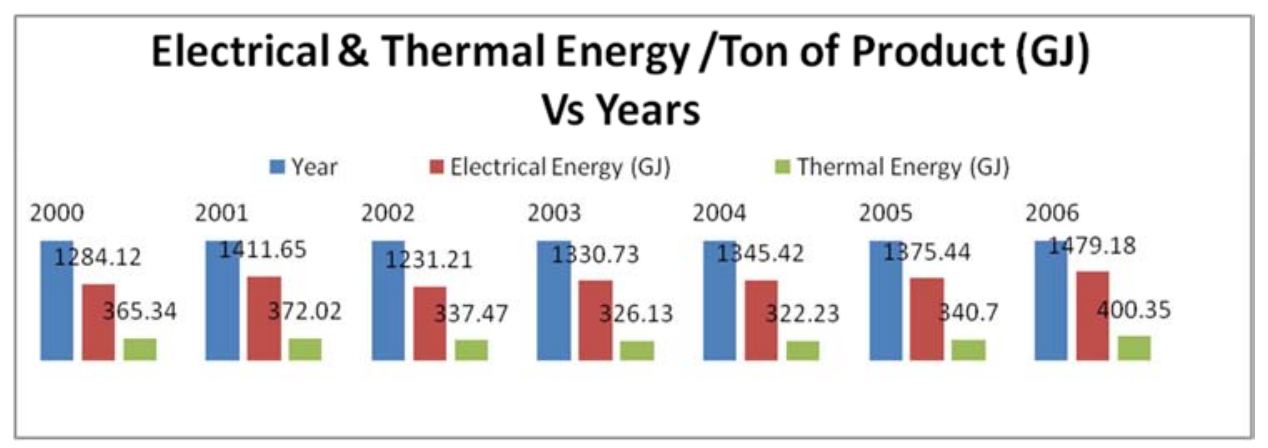

Figure 1. Electrical and Thermal Energy/Ton of Product (GJ) Vs Years.

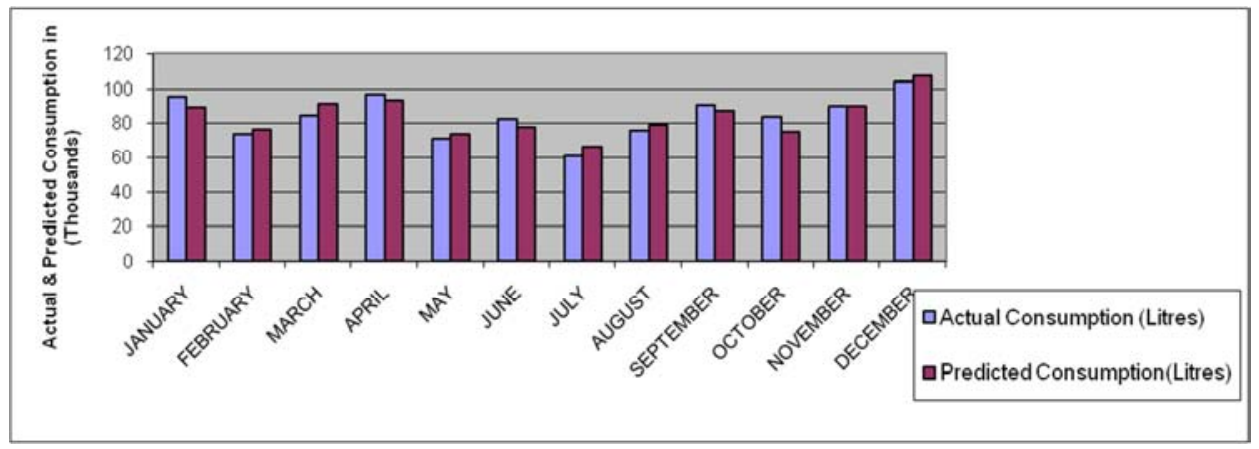

Figure 2. Actual and Predicted Fuel Energy Consumption (Litres) Vs Months.

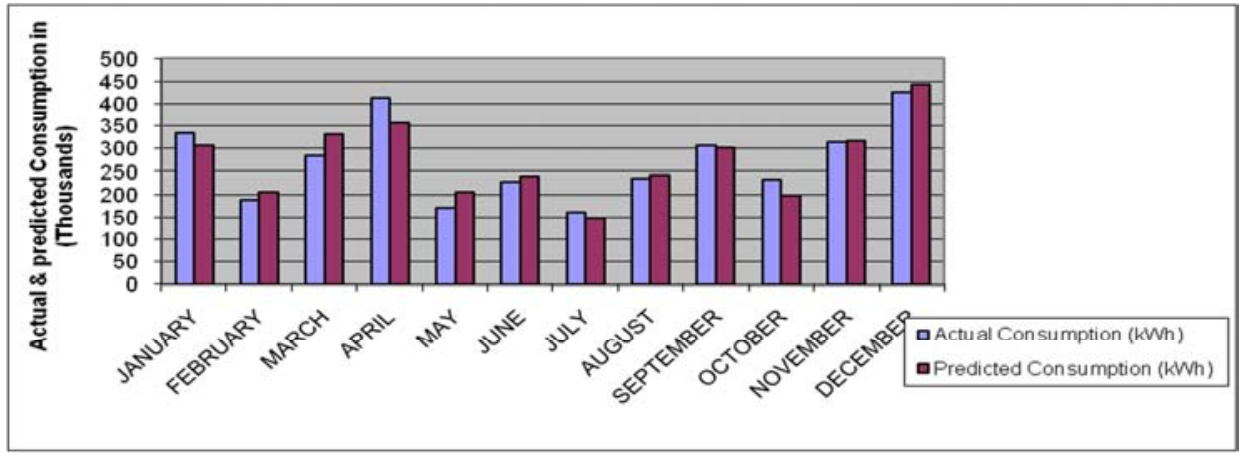

Figure 3. Actual and Predicted Electrical Energy Consumption (kWh) Vs Months.

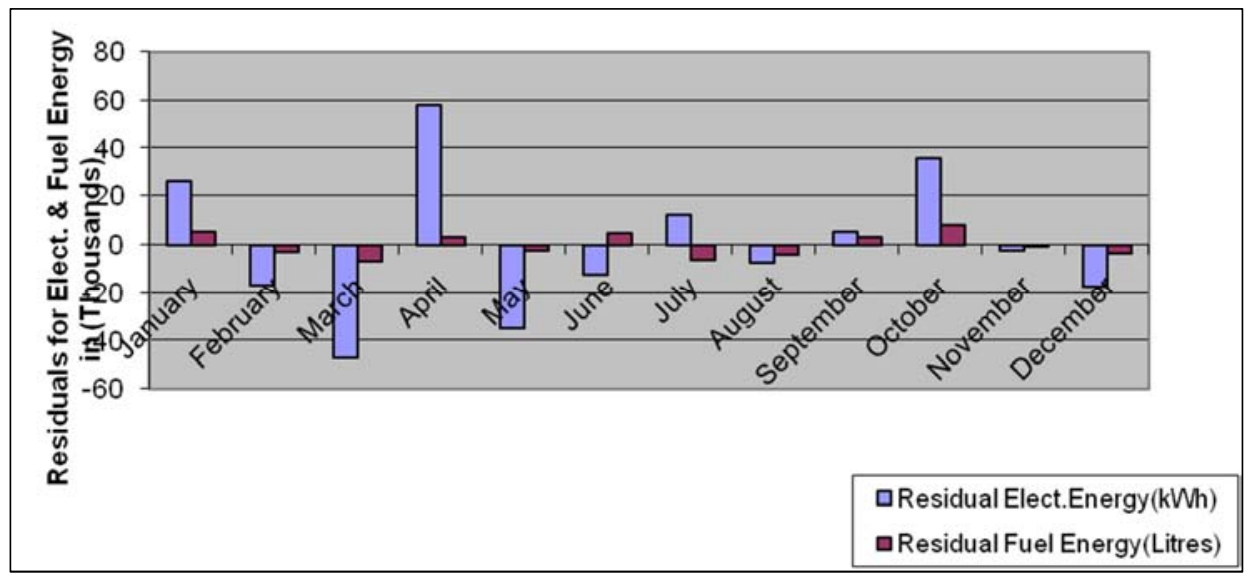

Figure 4. Residuals for Electrical and Fuel Energy Vs Months. 


\section{Conclusion}

In this study, regression equation model was developed for the electrical and fuel oil energy consumption for the period considered. The coefficient of determinant (R2) ranges from $0.703487-0.886193$ indicating strong correlation in energy consumption. The average percentage increase of electrical energy and fuel oil consumption for the period considered are $19.4 \%$ and $6.17 \%$ respectively while the average energy consumption per product tonne are $7.79 \mathrm{GJ} /$ Tonne for electrical energy and $22.73 \mathrm{GJ} /$ Tonne for fuel oil energy, this indicates that more energy is consumed in using fuel oil. Power factors were computed for the main electrical equipment (D. C main motors, electric furnace and compressor machine) the results of the power factors are $0.66,0.216$ and 0.303 respectively, from the results it shows that there is wastage of energy in electric furnace and compressor machine since the power factors are very low.

Finally, in calculating the savings in using an energy efficient motor of $95.0 \%$ as against a standard motor of $91.7 \%$ the amount in kilowatt that will be saved for the company was calculated to be $2.83 \mathrm{~kW}$ annually.

\section{References}

[1] Prasad, B \& Debasish B. (2014): "Energy Saving Technologies in Industries - An Overview". Journal of Scientific and Research Publications 4 (4) 1-6.

[2] Natarajan, K. (2015): "Some Strategies for Electrical Energy Conservation and Management in Induatries". Energy Engineering 112 (6), 33-45.

[3] Al-Zaharnah, I \& Hussain M. M. (2004): "Energy and Exergy use in Public and Private Sector of Saudi Arabia". Energy Policy 32, 1615-1624.

[4] Capehart, B. L., Turner, W. C \& Keneddy W. J. (2005) "Guide to Energy Management", Fifth Edition, Published by the Fairmont Press, Inc; India.
[5] Chan, D. Y, Yang, Hsu K.., Chein, M. \& Hong, G. (2005) "Current Situation of Energy Conservation in High Energy Consuming Industries Taiwan". Energy Policy, 35 (4), 202209.

[6] Hamed, D. A. \& Abdullahi W. E. (1992) "Energy Analysis and Conservation Prospects in the U. A. E Cement Industry". Journal of Energy Research, 16 (4), 75-83.

[7] Kramer, K J., Moll, H. C., Nonhebel, S., Wilting, H. C. (1999) "Greenhouse Gas Emission Related to Dutch Food Consumption". Energy Policy 27, 203-216.

[8] Lam, J. C., Chan, R. Y. C., Tsang, C. L \& Danny, H. W. L. (2003) "Electricity Use Characteristics of Purpose - Built Office Building in Subtropical Climates". Energy Conservation and Management, 45(3), 829-824.

[9] Murray, R. S., John J. S \& Alu R. S (2000) "Probability and Statistics", Second Edition, Published by Tata Mc Graw-Hill Publishing Company Limited.

[10] Omorogiuwa,. O. \& Ighalo G. I. (2006) Electrical Energy Consumption Pattern of West Africa Portland Cement Company, Ewekoro, Nigeria. Journal of Science, Engineering and Technology, 10 (1), 30-40.

[11] Pollio G. \& Uchida K. (1999) Management Background Corporate Governance and Industrial Restructuring: The Japanese Upstream Petroleum Industry. Energy Policy 27, 813-832.

[12] Ross M. (1987) Industrial Energy Conservation and Steel Industry of the United States. Energy 12, 1135-1152.

[13] Thollander P., Karlsson M., Soderstorm M. \& Creutz D. (2005) Reducing Industrial Energy Cost Through Energy Efficiency Measures in a Liberalized European Electricity Market: Case Study of a Swedish Iron Foundry. Applied Energy 81, 115-126.

[14] Ozdogan O. \& Arikol M. (1995) Energy and Exergy Analyses of Selected Turkish Industries. Energy- The International Journal 20, 73-80. 